\title{
Annually resolved climate signals in high-alpine ice cores
}

\author{
Margit Schwikowski, A. Eichler, T.M. Jenk and I. Mariani
}

\begin{abstract}
High-alpine ice cores offer great potential to obtain paleorecords with subannual resolution. However, calibration using instrumental data is often only possible at annual to multi-year resolution due to the strongly varying distribution of seasonal snowfall, post-depositional processes, and dating uncertainty.
\end{abstract}

High-alpine glaciers are generally characterized by high annual snow accumulation rates in the range of half a meter to several meters water equivalent, allowing paleorecords with subannual resolution to be obtained. A number of ice core parameters such as the stable isotope ratio of hydrogen or oxygen in the water $\left(\delta^{2} \mathrm{H}, \delta^{18} \mathrm{O}\right)$, the concentration of trace components (e.g. ammonium, mineral dust related compounds, black carbon), and the presence of melt layers vary with the seasons and have been used to identify annual layers. These variations are caused by the seasonality of temperature $\left(\delta^{2} \mathrm{H}, \delta^{18} \mathrm{O}\right.$, melt layers), precipitation $\left(\delta^{2} \mathrm{H}\right.$, $\delta^{18} \mathrm{O}$, mineral dust), or atmospheric transport and the emission source strengths of air pollutants (e.g. ammonium; Preunkert et al. 2000). However, even when subannually-resolved ice core records can be obtained, their calibration with climate indices remains difficult.

\section{Layer thinning with depth}

The depth-age relationship of high-alpine glaciers is strongly non-linear as annual layers become thinner with depth. This is due to plastic deformation of the ice under the weight of the overlying mass, resulting in horizontal ice flow that stretches the layers with increasing depth. Thinning rates are particularly high in cold glaciers where the ice is frozen to bedrock, whereas in polythermal glaciers the ice slides down to the ablation area before it thins strongly. Depending on precipitation rates, annual layers in the upper part of the glacier may consist of several meters of firn, whereas in the deeper part flow-induced thinning reduces the layers to a thickness of a few centimeters or even less (Fig. 1). Using analytical methods with high spatial resolution, such as measuring the electrical conductivity of the ice or counting the micro-particles present in dust bands formed during the dry season, over 800 years annual cycles were detect in the Illimani ice core from Bolivia (Knüsel et al. 2003) and up to 1300 years in the Quelccaya ice core from Peru (Thompson et al. 2013). In the future this may be extended even further back in time as recent developments with continuous flow analysis techniques now allow increasing the spatial resolution to the $\mathrm{mm}$ scale (Bigler et al. 2011). For this approach, a section of the ice core is melted continuously on a melt head, and the meltwater from the inner part, not contaminated by handling and prevented from contact with the modern environment, is directly fed into the respective analytical instrument to determine the concentration of trace components.

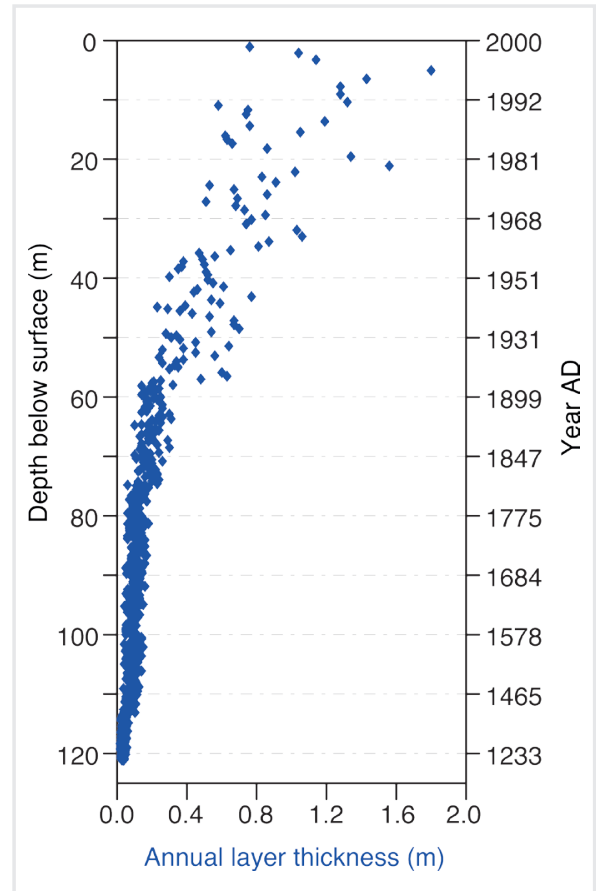

Figure 1: Annual layer thickness for the Illimani ice core from Bolivia as function of the depth below the ice surface and the associated age of the ice.

\section{Issues with seasonality and dating}

Due to the strong thinning of annual layers at depth, subannual information is only detectable in the upper part of the record, where ice-core dating can be performed by counting the successive annual layers. However, the seasonality of a recorded climatic variable may vary from year to year, according to meteorological conditions. For example, the minimum temperature as preserved in the Fiescherhorn $\delta^{18} \mathrm{O}$ record from the Swiss Alps (Fig. 2a) may have occurred in January, February or in some years even in December or March. Also, the stratification of the atmosphere controlling the concentration of ammonium by preventing vertical transport from the emission sources to glacier, which is used to distinguish winter from summer precipitation, may become unstable already in early spring in some years, but not until late spring in others.

Preservation of most parameters occurs only during precipitation. Accordingly the ice core record is strongly discontinuous at sites with high interannual variability of precipitation. In such cases only a precipitation weighted parameter, for example "precipitation weighted temperature", can be reconstructed (Brönnimann et al. 2013). But in most cases the seasonal distribution of precipitation is unknown for high-alpine sites, hence assumptions have to be made in order to dissect the record into seasonal or monthly data. Either constant seasonal distribution of precipitation is assumed or data from a nearby instrumental station at a lower elevation are used. However, both approaches introduce additional uncertainties to the interpretation of the paleoclimatic record (Mariani et al. 2012; Knüsel et al. 2005; Eichler et al. 2009).

The identification of annual layers can be ambiguous and result in dating uncertainties. Indeed, the formation of clear annual signals is often hampered by post-depositional wind erosion or surface melting and by the strongly varying distribution of snowfall in high-alpine environments. A further complication, which is confined to $\delta^{2} \mathrm{H}$ or $\delta^{18} \mathrm{O}$, is that the record is smoothed by diffusion during the snow-to-ice metamorphosis. In addition to annual layer counting, reference horizons such as the radioactivity peak resulting from nuclear weapon tests in the 1960s or tephra and aerosol layers caused by volcanic eruptions place additional dating constraints. While the measurement of peaks in radioactivity is relatively unambiguous, the identification of volcanic layers is not always straightforward given the high background level of the indicative chemical compounds such as sulfate in mid-latitude and low-latitude glaciers. To our knowledge, volcanic eruptions have not yet been identified in non-polar ice cores prior to AD 1258, probably because no major eruptions occurred for several centuries prior to this date and the volcanic signals cannot be resolved anymore further back in time due to ice layer thinning. Other chronologic methods, such as radiocarbon dating or ice flow modeling, are crucial for dating the lower parts of the records, but have uncertainties far above annual (Jenk et al. 2009; Lüthi and Funk 2000). Accordingly, dating uncertainty beyond the range of reference horizons quickly accumulates to several years and further increases with depth. With that dating uncertainty working at annual resolution becomes meaningless.

\section{Calibrating ice-core records}

Calibrating ice-core proxy records directly with instrumental data on an annual timescale is difficult. For example the high accumulation Fiescherhorn site provides paleodata with subannual resolution during the recent time 

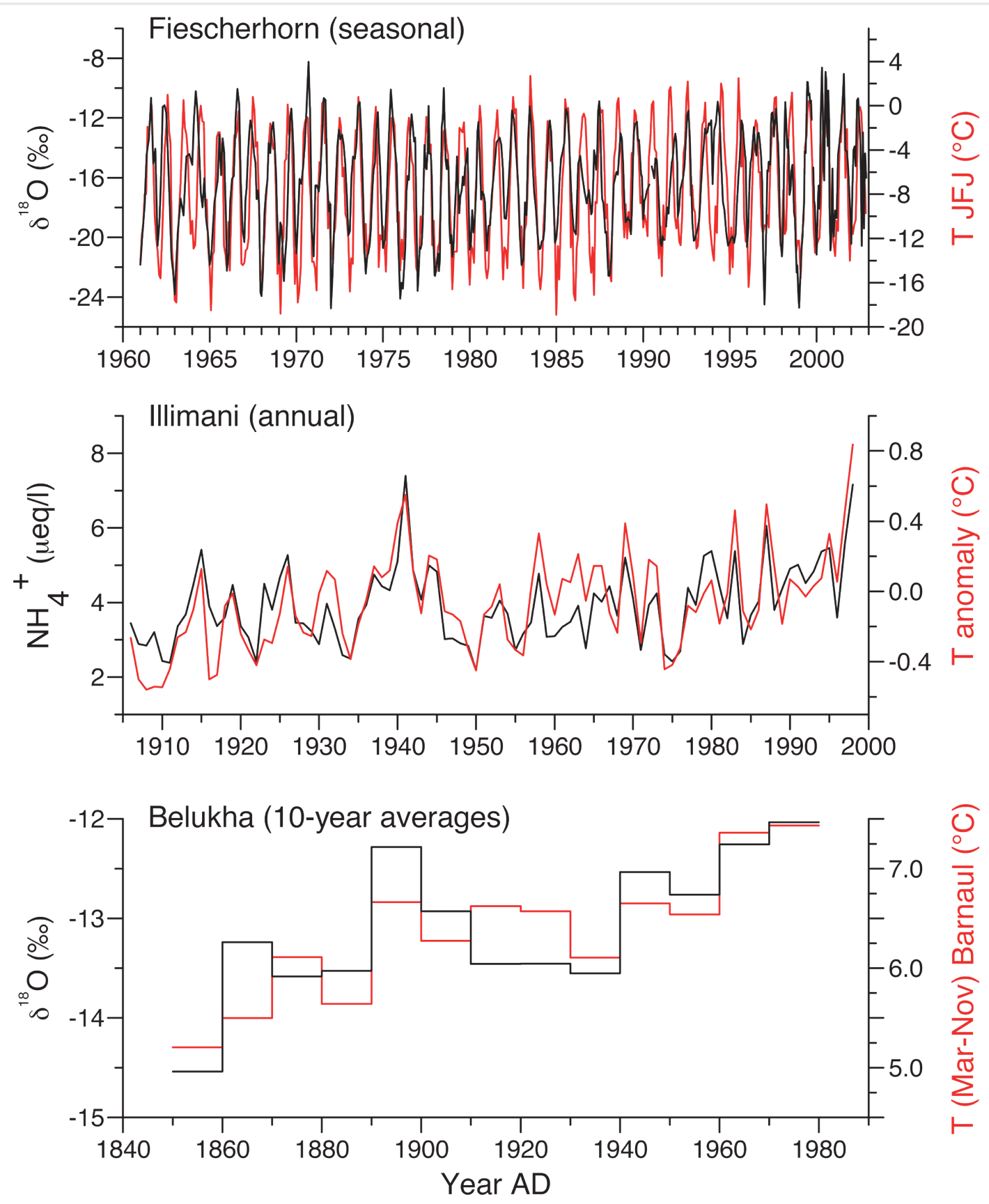

Figure 2: Calibration of ice core data (black) with instrumental temperatures (red) at different resolution: (A) Fiescherhorn ice core $\delta^{18} \mathrm{O}$ and Jungfraujoch (JFJ) temperature (seasonal values; Mariani et al. 2012), Switzerland (B) Illimani ice core $\mathrm{NH}_{4}^{+}$and HadCRUT3 (Amazon subset: $82-34^{\circ} \mathrm{W}, 12-20^{\circ} \mathrm{S}$ ) temperature (annual values; Kellerhals et al. 2010), Bolivia, and (C) Belukha ice core $\delta^{18} \mathrm{O}$ and Barnaul (March-November) temperature (10-year averages; Eichler et al. 2009), Russia.

period (1961-2001). Temperature records from the nearby Jungfraujoch station are highly correlated with the Fiescherhorn seasonal $\delta^{18} \mathrm{O}$ record (Fig. 2a, n=164, r=0.70, p<0.001). However, this correlation is lost after subtracting the seasonal cycle $(r=0.09)$, due to the dating uncertainty of \pm 1 year and changes in seasonal precipitation.

In fact, only a few studies have successfully calibrated ice-core proxy records directly with instrumental data on an annual timescale (e.g. Kaspari et al. 2007; Kellerhals et al. 2010). An example comes from Illimani ice core, where annual $\mathrm{NH}_{4}^{+}$concentrations were used as a temperature proxy for the first time (Fig. 2b). Ice core records are often smoothed (e.g. multi-year average) before calibration. This is done to minimize the effect of potential dating offsets of the ice core data from meteorological records. For example, the correlation of the Belukha ice core $\delta^{18} \mathrm{O}$ record with instrumental temperature data from the Barnaul station (both Russia) was significant only for the 10year averages but not at higher time resolutions (Fig. 2c; Eichler et al. 2009).

Another attempt to get a more robust dataset with smaller dating uncertainty is to stack several independently dated ice cores (Bohleber et al. 2013). However, even then, the relationship with direct observations from instrumental data is best captured on multi-annual time scales. Accordingly, results and data sets are commonly not presented in subannual and annual resolution.

\section{AFFILIATIONS}

Paul Scherrer Institut and Oeschger Centre for Climate Change Research, University of Bern, Switzerland

\section{CONTACT}

Margit Schwikowski: margit.schwikowski@psi.ch

\section{SELECTED REFERENCES}

Full reference list under:

http://www.pages-igbp.org/products/newsletters/ ref2014_1.pdf

Bigler M et al. (2011) Environ Sci Technol 45: 4483-4489 Bohleber P et al. (2013) Tellus B 65, doi: 10.3402/tellusb. v65i0.20148

Eichler A et al. (2009) Geophys Res Lett 36, doi: 10.1029/2008GL035930

Kellerhals T et al. (2010) J Geophys Res 115, doi: 10.1029/2009JD012603

Mariani I et al. (2012) Clim Past Discuss 8: 5867-5891 